\title{
Autophagy drives osteogenic differentiation of human gingival mesenchymal stem cells
}

\author{
Chiara Vidoni ${ }^{1}$, Alessandra Ferraresi ${ }^{1}$, Eleonora Secomandi ${ }^{1}$, Letizia Vallino ${ }^{1}$, Chiara Gardin², Barbara Zavan ${ }^{2,3}$, \\ Carmen Mortellaro ${ }^{4}$ and Ciro Isidoro ${ }^{1 *}$ id
}

\begin{abstract}
Background/aim: Autophagy is a macromolecular degradation process playing a pivotal role in the maintenance of stem-like features and in the morpho-functional remodeling of the tissues undergoing differentiation. In this work we investigated the involvement of autophagy in the osteogenic differentiation of mesenchymal stem cells originated from human gingiva (HGMSC). METHODS: To promote the osteogenic differentiation of HGMSCs we employed resveratrol, a nutraceutical known to modulate autophagy and cell differentiation, together with osteoblastic inductive factors. Osteoblastic differentiation and autophagy were monitored through western blotting and immunofluorescence staining of specific markers.
\end{abstract}

Results: We show that HGMSCs can differentiate into osteoblasts when cultured in the presence of appropriate factors and that resveratrol accelerates this process by up-regulating autophagy. The prolonged incubation with dexamethasone, $\beta$-glycerophosphate and ascorbic acid induced the osteogenic differentiation of HGMSCc with increased expression of autophagy markers. Resveratrol $(1 \mu \mathrm{M})$ alone elicited a less marked osteogenic differentiation yet it greatly induced autophagy and, when added to the osteogenic differentiation factors, it provoked a synergistic effect. Resveratrol and osteogenic inductive factors synergistically induced the AMPK-BECLIN1 pro-autophagic pathway in differentiating HGMSCs, that was thereafter downregulated in osteoblastic differentiated cells. Pharmacologic inhibition of BECLIN-1-dependent autophagy precluded the osteogenic differentiation of HGMSCs.

Conclusions: Autophagy modulation is instrumental for osteoblastic differentiation of HGMSCs. The present findings can be translated into the regenerative cell therapy of maxillary / mandibular bone defects.

Keywords: AMPK, BECLIN-1, Phytotherapy, Osteoblast, Resveratrol

\section{Background}

Bone resorption, bone wound healing and osteo-integration of implants remain major clinical challenges in orthopedics and dentistry. An attractive solution is exploiting the regenerative potential of Mesenchymal Stem Cells (MSCs) isolated from adult tissues that could differentiate into osteoblasts and chondrocytes [1-3]. In this context, interest recently arose for MSCs from the lamina propria of the gingiva (GMSCs), that represents an easily

\footnotetext{
* Correspondence: ciro.isidoro@med.uniupo.it

'Laboratory of Molecular Pathology, Department of Health Sciences,

Università del Piemonte Orientale "A. Avogadro", Via P. Solaroli 17, 28100

Novara, Italy

Full list of author information is available at the end of the article
}

accessible source from which MSCs can be isolated with minimally invasive techniques [4-6]. GMSCs can be propagated in vitro for long-time while maintaining a stable phenotype and can be induced to differentiate into the osteogenic lineage employing a variety of substances, including herbal-derived polyphenols [7-11].

Recently, interest arose for the potential of resveratrol (RV, trans 3,5,4' trihydroxy-stylbene), a naturally occurring polyphenol, to prevent and cure bone loss-related diseases [12, 13]. RV shows anti-inflammatory [14] and antiosteoclastic activities $[15,16]$ while showing osteoblastic differentiation promoting activities on MSCs [17-21].

(C) The Author(s). 2019 Open Access This article is distributed under the terms of the Creative Commons Attribution 4.0 International License (http://creativecommons.org/licenses/by/4.0/), which permits unrestricted use, distribution, and 
However, the osteogenic response to RV has not been tested yet in human GMSCs (HGMSCs).

Stem cell differentiation implies a morpho-functional remodeling of the cell that is accomplished through dynamic and coordinated processes of macromolecular degradation and synthesis along with transcriptional and epigenetic reprogramming [22-24]. Macromolecular degradation in stem cells undergoing differentiation occurs via macro-autophagy (now on simply autophagy), which consists in the entrapment of cellular components such as organelles, membranes and cytosolic proteins within a double-membrane vesicle (the autophagosome) that will eventually fuse with lysosomes to form an autolysosome wherein the substrates will be degraded to completion [24, 25]. Autophagy is a stress-response and homeostatic process that plays a pivotal role in bone homeostasis [26]. However, whether and how autophagy is implicated in the osteogenic differentiation of MSCs remains to be elucidated yet. Here, we have investigated the functional role and the regulation of autophagy during the osteogenic differentiation of HGMSCs using RV as an inducer of autophagy [27] and of osteogenic differentiation of MSCs [18] at the same time. We show that RV synergizes with osteogenic inductive factors to accelerate the osteogenic differentiation of HGMSCs and that this effect is strictly dependent on the modulation of autophagy.

\section{Methods}

\section{Isolation of human gingival mesenchymal stem cells}

Human Gingival Mesenchymal Stem Cells (HGMSCs) were isolated from gingival tissue samples of adult healthy patients undergoing orthodontic surgery procedures. Each subject gave written informed consent, in accordance with the Helsinki Declaration, before their inclusion in the study. The Ethical Committee of Padova Hospital (Padova, Italy) approved the research protocol. After collection, gingival biopsies were briefly washed with Phosphate Buffered Saline (PBS; EuroClone, Milan, Italy), minced, then enzymatically digested with a solution of $3 \mathrm{mg} / \mathrm{mL}$ collagenase type I (Sigma-Aldrich, Saint Louis, MO, USA) and $4 \mathrm{mg} / \mathrm{mL}$ dispase (Sigma-Aldrich) in PBS for $2 \mathrm{~h}$ at $37^{\circ} \mathrm{C}$, as described elsewhere [28]. Once digested, the solution was filtered through $70 \mathrm{~mm}$ Falcon strainers (Becton \& Dickinson, Franklin Lakes, NJ). The isolated cells were then cultured with Dulbecco's Modified Eagle's Medium (DMEM) high glucose (EuroClone), supplemented with 10\% Fetal Bovine Serum (FBS; EuroClone), and 1\% penicillin/streptomycin (P/S; EuroClone). Culture medium was refreshed twice a week. At $80-90 \%$ confluence, cells were detached with trypsin-EDTA solution (Sigma-Aldrich) and passaged repeatedly.

\section{Characterization of HGMSCs by flow cytometry}

Adherent cells at passage 3 were dissociated and resuspended in flow cytometry staining buffer (R\&D Systems, Minneapolis, MN, USA) at a final cell concentration of $1 \times 10^{6}$ cells $/ \mathrm{mL}$. For surface markers characterization, the following fluorescent monoclonal mouse anti-human antibodies were used: CD73 APC (eBioscience ${ }^{\mathrm{Tw}}$, Thermo Fisher Scientific, San Diego, CA, USA), CD90 BV510 (BD Biosciences, San Jose, CA, USA), CD105 PE-Cyanine7 (eBioscience $\left.{ }^{\mathrm{Tm}}\right)$, CD14 PE (eBioscience $\left.{ }^{\mathrm{Tm}}\right)$, CD34 APC-eFluor 780 (eBioscienceTM), and CD45 Pacific Orange (Thermo Fisher Scientific), as published elsewhere [29]. Cells were washed twice with $2 \mathrm{~mL}$ of flow cytometry staining buffer and resuspended in $500 \mu \mathrm{L}$ of flow cytometry staining buffer. Fluorescence was evaluated by flow cytometry in Attune NxT flow cytometer (Thermo Fisher Scientific). Data were analyzed using Attune NxT software (Thermo Fisher Scientific).

\section{Cell culture and reagents}

HGMSCs were cultivated under standard conditions $\left(37^{\circ} \mathrm{C}, 95 \%\right.$ air: $\left.5 \% \mathrm{CO}_{2} \mathrm{v} / \mathrm{v}\right)$ in $\alpha$-Minimum Essential Medium Eagle ( $\alpha$-MEM, Cod. M8042, Sigma-Aldrich, St. Luis, MO, USA) supplemented with $10 \%$ heat-inactivated Fetal Bovine Serum (FBS, cod. ECS0180L; Euroclone S.p.A., Milan, Italy), $2 \mathrm{mML}$-glutamine (cod. G7513, Sigma-Aldrich) and 1\% w/v of Penicillin/Streptomycin (cod. P0781, Sigma-Aldrich). For osteogenic differentiation, cells were incubated up to 21 days in $\alpha$ MEM supplemented with $50 \mu \mathrm{g} / \mathrm{mL}$ of L-ascorbic acid 2-phosphate (Cod. 49,752, Sigma-Aldrich), $100 \mathrm{nM}$ of dexamethasone (Cod. D1756, Sigma-Aldrich), and 10 $\mathrm{mM}$ of $\beta$-glycerophosphate (Cod. G9422, Sigma-Aldrich) (referred to as 'differentiation medium') [30]. Differentiation medium was replaced twice or thrice a week by adding all previous reagents. Resveratrol (RV, Cod. R5010, Sigma-Aldrich) was added to the standard or differentiation medium as indicated. Where reported, $5 \mu \mathrm{M}$ spautin-1 (Sp1, Cod. SML0440, Sigma-Aldrich) was added to the culture medium.

HGMSCs were seeded on $35 \mathrm{~mm}$ Petri dishes at 80.000 cells per dish or on sterile glass coverslips at 10.000 cells per dish for western blot and immunofluorescence analysis, respectively. For histochemical staining with Alizarin Red Staining, the cells were cultured on 24-well plates at 20.000 cells per well and let adhere 24 $\mathrm{h}$ before treatments.

\section{Antibodies}

The following primary antibodies were employed for western blotting and immunofluorescence techniques: rabbit monoclonal anti-RUNX2 (Cod. 12,556, Cell Signaling Technology Inc., Danvers, MA, USA), rabbit 
polyclonal anti-collagen Type 1 alpha 1 (Cod. NB600408, Novus Biological Centennial, USA), mouse monoclonal anti-osteopontin (Cod. MA5-17180, Thermo Fisher Scientific Inc., Waltham, MA, USA), mouse monoclonal anti-osteocalcin (Cod. sc-74,495, Santa Cruz Biotechnology Inc., Dallas, TX, USA), mouse monoclonal antibeclin-1 (Cod. 612,112, BD Biosciences, San Jose, CA, USA), rabbit monoclonal anti-phospho-beclin-1 (Ser93) (Cod. 14,717, Cell Signaling Technology Inc.), rabbit monoclonal anti-PI3 Kinase Class III (Vps34, Cod. 4263, Cell Signaling Technology Inc.), rabbit polyclonal antiLC3B (Cod. L7543, Sigma-Aldrich), mouse monoclonal anti- $\beta$-tubulin (Cod. T5293, Sigma-Aldrich Corp.), mouse monoclonal anti- $\beta$-actin (Cod. A5441, Sigma-Aldrich), mouse monoclonal anti-LAMP1 (Cod. 555,798, Becton, Dickinson and Company, New Jersey, NJ, USA), rabbit polyclonal anti-AMPK $\alpha$ (Cod. 2532, Cell Signaling Technology Inc.) and rabbit monoclonal anti-phospho-AMPK $\alpha$ (Thr172) (Cod. 2535, Cell Signaling Technology Inc.).

\section{Western blotting}

HGMSCs were homogenized in RIPA buffer (0.5\% deoxycholate, 1\% NP-40, 0.1\% Sodium Dodecyl Sulfate in PBS solution) supplemented with protease inhibitor cocktail and phosphatase inhibitors $\left(\mathrm{Na}_{3} \mathrm{VO}_{4}\right.$ and $\left.\mathrm{NaF}\right)$. Proteins were determined by Bradford assay, denatured with $5 \mathrm{X}$ Loading buffer at $95^{\circ} \mathrm{C}$ for $10 \mathrm{~min}$ and fractionated by SDS-PAGE at different acrylamide percentage $(15,12.5$, $8 \%$ or $6 \%$ ) according to the m.w. of the target protein. Molecular weight markers were PageRuler Prestained Protein Ladder (Cod. 26,616, Thermo Fisher Scientific Inc.) for 15 and $12.5 \%$ gels, and Spectra Multicolor High Range Protein Ladder (cod. 26,625, Thermo Fisher Scientific Inc.) for 8 and $6 \%$ gels. After PAGE, the proteins were blotted onto PVDF membranes (cod. 162-0177, Bio-Rad, Hercules, CA, USA). Membranes were blocked with 5\% non-fat milk (cod. 68,514-61-4, SERVA Electrophoresis GmbH, Heidelberg, Germany) containing 0.2\% Tween-20 for $1 \mathrm{~h}$ at room temperature (RT), incubated with specific primary antibody overnight at $4{ }^{\circ} \mathrm{C}$ and, thereafter, with the secondary HRP-conjugated antibody for at least $1 \mathrm{~h}$ at RT. $\beta$-tubulin and $\beta$-actin were used as homogenate protein loading control. Membranes were developed with the enhanced chemiluminescence method (ECL, cod. NEL103E001 EA; PerkinElmer Inc., Waltham, MA, USA). The relative band intensity was acquired with the VersaDOC Imaging System apparatus (Bio-Rad) and quantified by Quantity One 4.5.0 software (Bio-Rad). At least three independent replicates per each western blot were performed.

\section{Immunofluorescence}

HGMSCs plated on sterile coverslips were incubated as indicated. At the end, the cells were washed with PBS, fixed with ice-cold 100\% methanol and permeabilized with $0.2 \%$ Triton X-100 in PBS for $10 \mathrm{~min}$. Then, cells were incubated with the specific primary antibodies overnight at $4{ }^{\circ} \mathrm{C}$. The following day, the coverslips were washed with $0.1 \%$ Triton X-100 in PBS and incubated for $1 \mathrm{~h}$ at RT with goat-anti-rabbit IgG Alexa Fluor ${ }^{\mathrm{Tm}}$ plus 488 (Cod. A32731, Thermo Fisher Scientific Inc.) or goat-anti-mouse IgG Alexa Fluor $^{\text {Tw }}$ plus 555 (Cod. A32727, Thermo Fisher Scientific Inc.) secondary antibodies, as appropriate. Nuclei were stained with DAPI (4',6-diamidino-2-phenylindole, cod. 32,670, Sigma-Aldrich Corp.). Thereafter, coverslips were mounted onto glasses using slow-FADE anti-FADe reagent (Cod. S36936, Life Technologies Ltd) and fluorescence images were acquired with the Leica DMI6000 fluorescence microscope (Leica Microsystems AG, Wetzlad, DE). The fluorescence intensity was measured by Image-J $1.48 \mathrm{v}$ software (http://imagej.nih.gov/ij/) and indicated as IntDen, for either single channel and co-labelling (red + green $=$ yellow). IntDen (Integrated Density) refers to the average value of fluorescence in a selected area normalized to the number of cells. At least three slides were prepared for each experimental condition and fluorescence in up to 100-200 cells in total present in six to ten microscopic fields randomly chosen was quantified. Images shown are representative of at least three separate experiments.

\section{Assessment of osteogenic differentiation}

The presence of calcium deposition in the extracellular matrix, a sign of osteoblastic activity, was detected by Alizarin Red S staining [31]. At the end of incubation in medium containing or not the osteogenic differentiation factors and/or resveratrol, the cell culture was washed with PBS, fixed in 10\% formaldehyde for $30 \mathrm{~min}$ at room temperature (RT), rinsed twice with deionized water and stained with $40 \mathrm{mM}$ Alizarin Red S (Cod. TMS-008-C, Sigma-Aldrich), $\mathrm{pH} 4.1$, for $45 \mathrm{~min}$ at RT. Then, the cultures were washed four times with deionized water to remove non-specifically bound stain. After drying, stained monolayers were observed and imaged under the phase microscope. The area of calcium deposits, indicated as Calcium Deposition (\% Area), was calculated using the Image-J $1.48 \mathrm{v}$ software.

\section{Statistics}

All experiments were performed at least three times, separately. Data in histograms are shown as average \pm S.D. GraphPad Prism was employed (GraphPad Software Inc.) for statistical analysis. Statistical significance of the data was given by one-way ANOVA analysis of variance followed by Tukey's test. Differences were considered significant for ${ }^{*} p<0.05$; *** $p<0.01$; **** $p<0.001$. 


\section{Results}

\section{Characterization of human gingival mesenchymal stem} cells

The HGMSCs isolated from the gingival samples were characterized according to their surface protein expression by flow cytometry. As shown in Fig. 1, the cells were found positive for the established MSCs-specific surface markers CD73, CD90, and CD105 [32]. Flow cytometry immunophenotyping also revealed the negativity to CD14, CD34, and CD45, confirming the absence of hematopoietic cells in the isolated stem cells population.

\section{Resveratrol promotes the osteogenic differentiation of} human gingival mesenchymal stem cells

To determine the optimal conditions for osteogenic differentiation by RV, HGMSCs were incubated for up to 21 days with RV in concentration ranging from 1 to $100 \mu \mathrm{M}$. As positive control, the cells were incubated in a medium

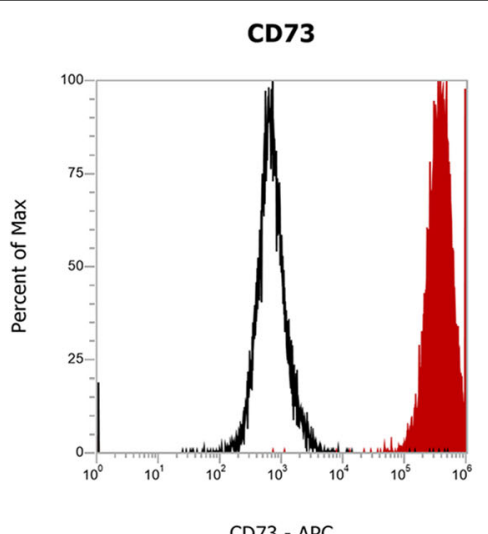

CD73 - APC

CD105

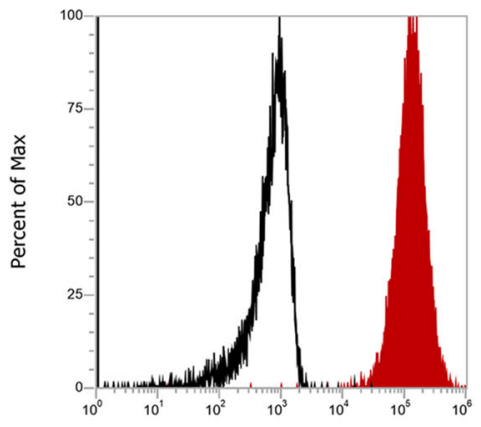

CD105 - PE-Cy7

CD34

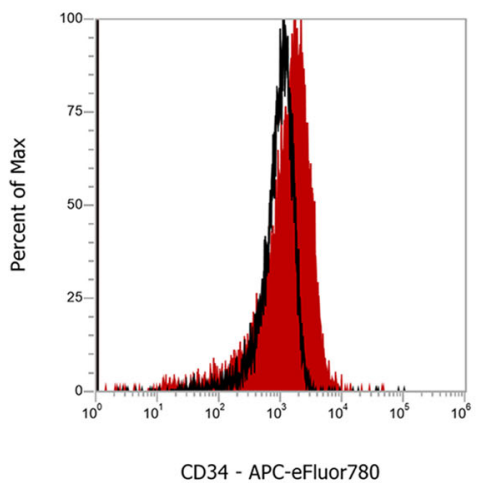

CD90

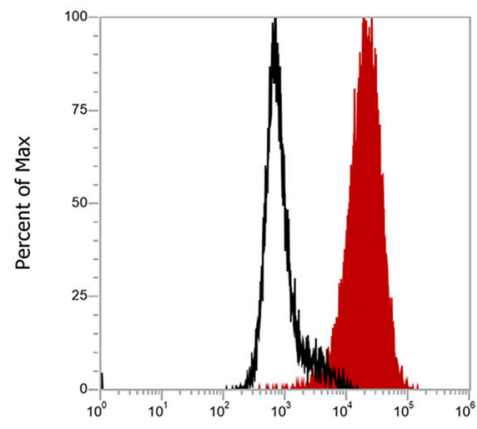

CD90 - BV510

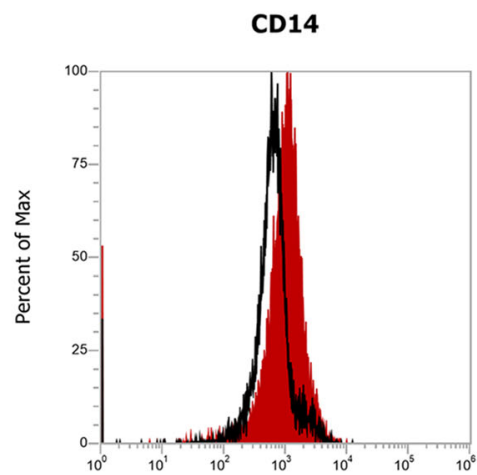

CD14 - R-PE

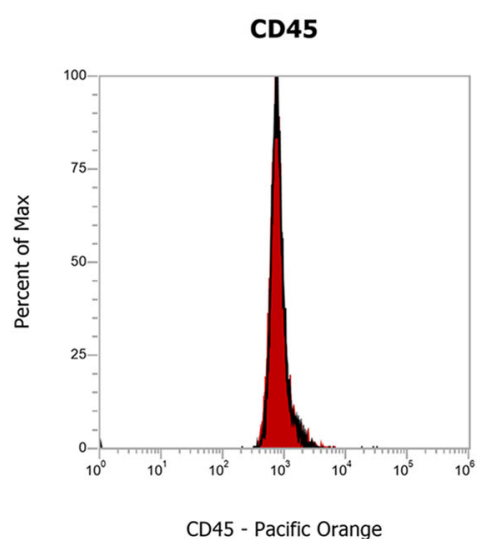

Fig. 1 Isolation and characterization of Human Gingival Mesenchymal Stem Cells. Characterization of cell surface markers in HGMSCs at passage 3 by flow cytometry. The stem cells isolated from the gingival biopsies are positive to CD73, CD90, and CD105 MSCs-specific markers, and negative to CD14, CD34, and CD45 hematopoietic markers 
supplemented with the osteogenic differentiation factors dexamethasone, $\beta$-glycerophosphate and ascorbic acid (from now on, referred as 'differentiation medium'). To monitor the mineralization associated with osteogenic differentiation of HGMSCs the cultures were stained with Alizarin Red S to detect the calcium deposits in the extracellular space. The mineralization was clearly detectable after a minimum of 7-14 days culture in differentiation medium (not shown). Representative images in Fig. 2 (and relative quantification) show that the osteogenic differentiation promoted by RV is maximal at $1 \mu \mathrm{M}$ and declines when concentration raises up to $100 \mu \mathrm{M}$, which turned out to be toxic. When $1 \mu \mathrm{M}$ RV was added to the differentiation medium, osteogenic differentiation of HGMSCs (as mirrored by the mineralization of the extracellular matrix) was accelerated, indicating a synergism between RV and osteogenic differentiation factors (Fig. 3). To characterize at molecular level this effect, we analyzed the expression of signaling and structural protein markers of the osteogenic differentiation [33]. Western blotting showed that RUNX2, the transcription factor of osteocalcin $(\mathrm{OCN})$ and of other genes associated with osteoblast differentiation, [34, 35] was upregulated in the HGMSCs cultured in the differentiation medium or in the presence of RV alone (though to a lower extent in the latter case) (Fig. 4). Interestingly, when $\mathrm{RV}$ was added to the differentiation medium, the expression of RUNX2 was further induced compared to the culture conditions in either the differentiation medium or RV

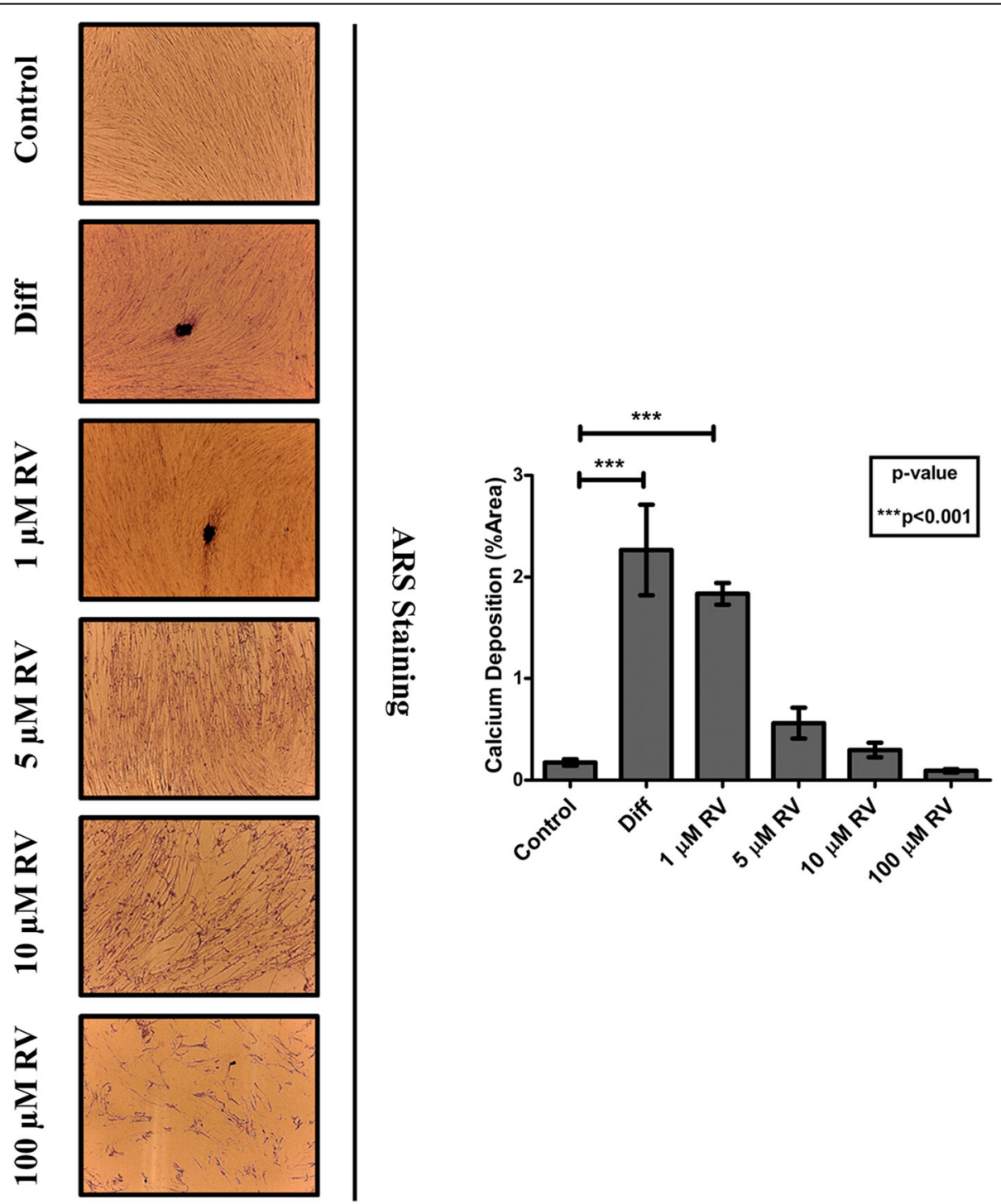

Fig. 2 Resveratrol promotes the osteoblastic differentiation of Human Gingival Mesenchymal Stem Cells. Adherent HGMSCs were cultured for 21 days in control medium supplemented or not with resveratrol (RV) at the indicated concentration or in differentiation medium (Diff) containing the three osteoblastic inductive factors dexamethasone, $\beta$ - glycerophosphate and ascorbic acid. At the end, the cultures were processed for Alizarin Red S staining of extracellular calcium deposits. The stained area was quantified using the ImageJ software 


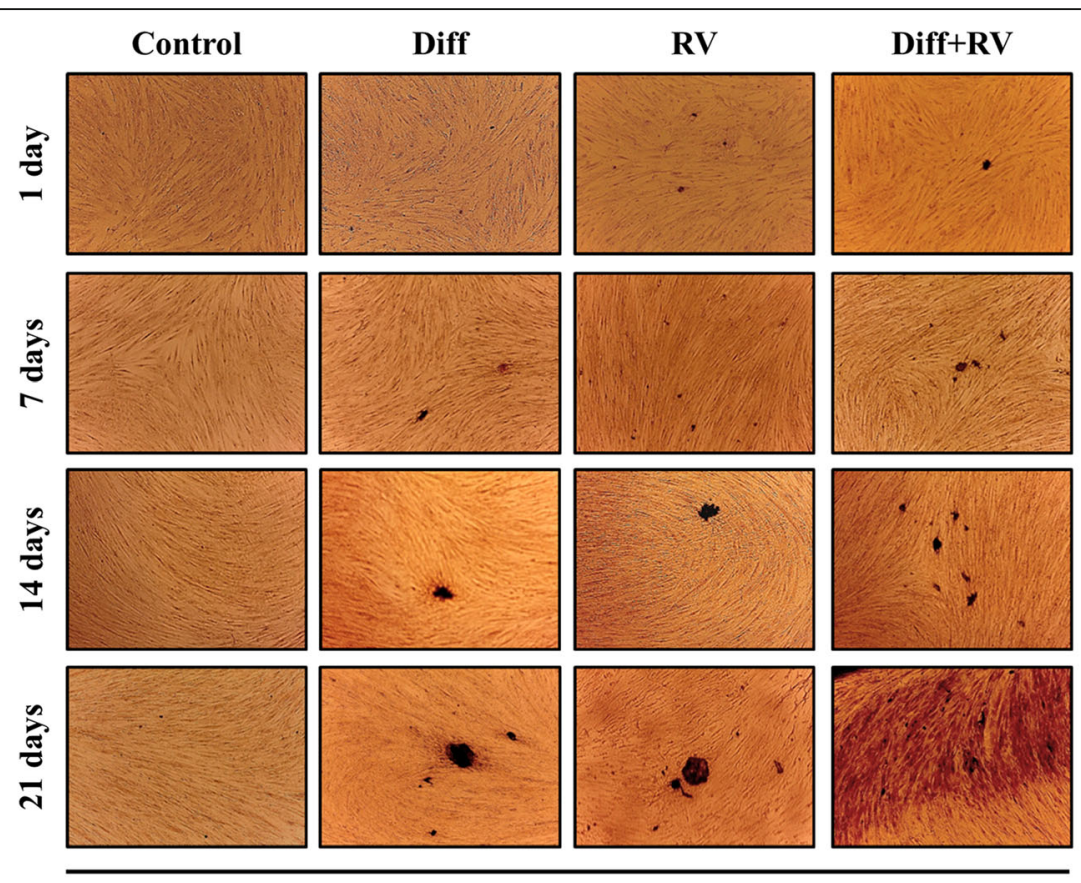

ARS Staining
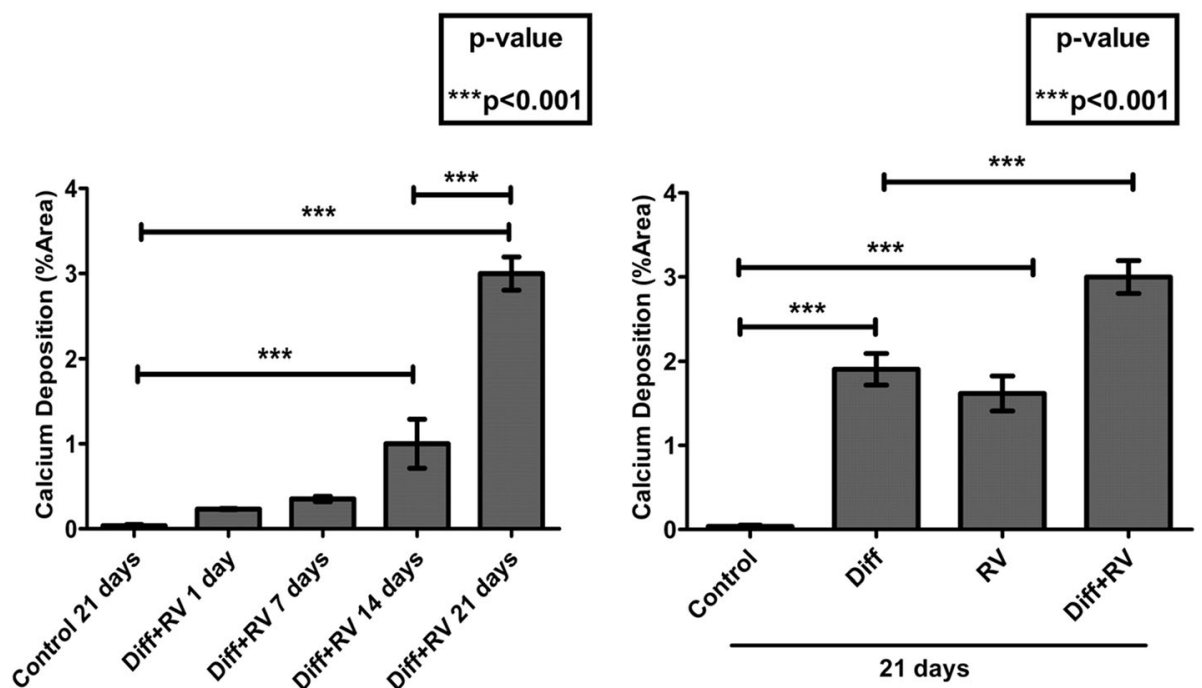

Fig. 3 Resveratrol synergizes with osteogenic inductive factors to accelerate osteoblastic differentiation of Human Gingival Mesenchymal Stem Cells. Adherent HGMSCs were cultured for 1 to 21 days in control medium or in differentiation medium (Diff) supplemented or not with $1 \mu \mathrm{M}$ resveratrol (RV). At the end, the cultures were processed for Alizarin Red S staining of extracellular calcium deposits. Quantification of stained area in the time-course is reported in the histogram

alone (Fig. 4). The combined expression of collagen 1 (COL1A1) and of osteopontin (OPN) is suggestive of differentiation of MSCs toward the osteogenic line, while OCN synthesis is switched on in osteoblasts and its expression is therefore proofing that osteoblast differentiation indeed occurred [33]. Compared to the osteogenic inductive factors, $\mathrm{RV}$ alone elicited a slight increase in the expression of these markers (Fig. 4). However, when RV was added to the osteogenic differentiation medium it greatly stimulated the expression of these three proteins in a synergistic manner with the osteogenic factors (Fig. 4). To prove further the acquisition of an osteogenic phenotype by HGMSCs under these culture conditions, we performed the immunofluorescence co-staining of the above markers. Representative images and their quantification are shown in Fig. 5. The data confirm that after 21 days of treatment with $1 \mu \mathrm{M}$ RV alone the expression of these markers was weakly induced, while the addition of RV to the osteogenic differentiation medium 

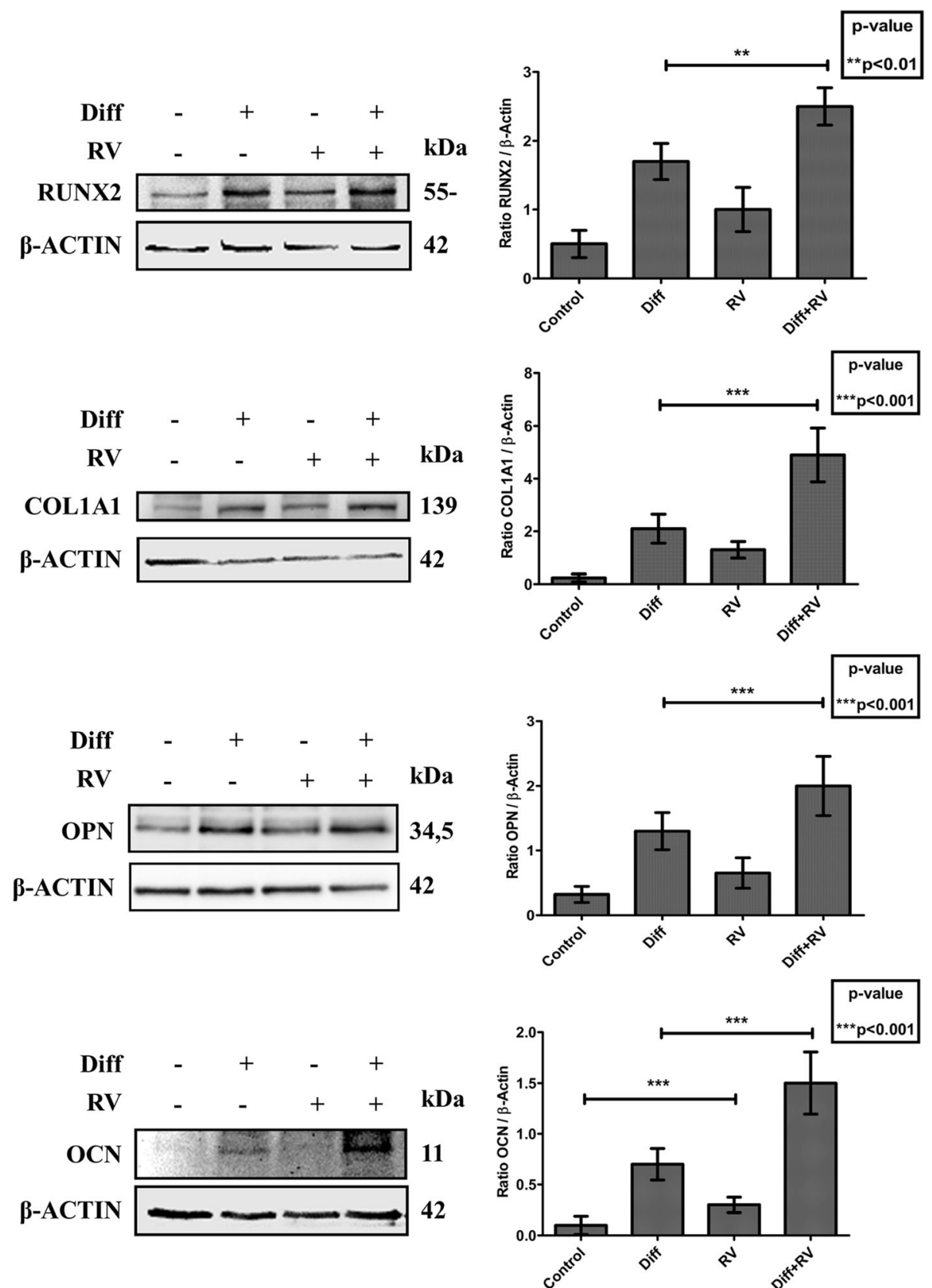

Fig. 4 Expression of osteoblastic differentiation markers in Human Gingival Mesenchymal Stem Cells. Adherent HGMSCs were cultured for 21 days in control medium or in differentiation medium (Diff) supplemented or not with $1 \mu \mathrm{M}$ resveratrol (RV). At the end, cell homogenates were processed for western blotting analysis of the expression of the osteoblastic transcription factor RUNX-2 and of the osteogenic differentiation markers COL1A1, OPN and OCN. Densitometry of the specific bands (average \pm S.D.) of three independent experiments is shown in the histograms

synergistically augmented their expression in the cells. Noteworthy, RV greatly stimulated the nuclear translocation of RUNX2 (Fig. 5a).

\section{Osteogenic differentiation of human gingival mesenchymal} stem cells associates with induction of autophagy

To see if autophagy is involved in the osteogenic differentiation of HGMSCs we first performed the immunofluorescence staining of autophagic vacuoles with antibodies specific to LC3, a lipidated protein specifically associated with the membranes of the autophagosomes, and to LAMP1, an integral protein of the lysosomal membranes [36]. The co-labeling marks the autolysosome and is indicative of the effective fusion of autophagosomes with lysosomes. Representative images taken at day 1 and day 21 are shown in Fig. 6. ImageJ quantification of co-labeled 


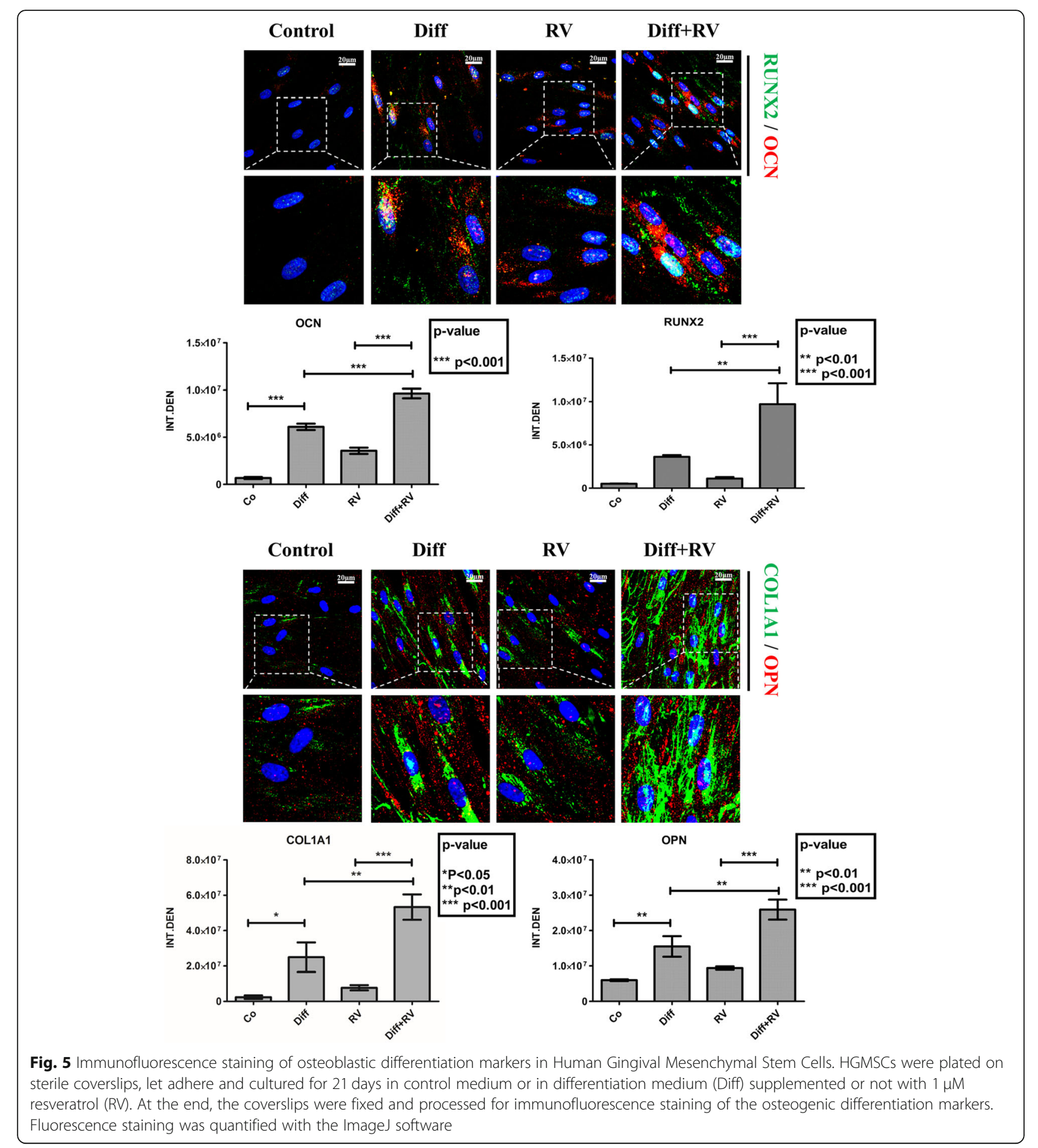

vesicles (autolysosomes) indicated that the autophagy flux was greatly and promptly (since day 1 ) stimulated by RV, while it was initially (at day 1 ) downregulated and later (at day 21) induced by the osteogenic differentiation factors. Remarkably, the formation and accumulation of autolysosomes were greatly stimulated in the cells cultured in differentiation medium supplemented with RV (Fig. 6). As a further proof of the induction of autophagy during HGMSCs differentiation, we analyzed the AMPKBECLIN-1 pathway, as primary candidate of the signaling pathway triggered by RV [37]. It was found that under osteogenic inductive culture conditions AMPK was active and, particularly, BECLIN-1 was synergistically activated by the combination of RV and osteogenic differentiation 

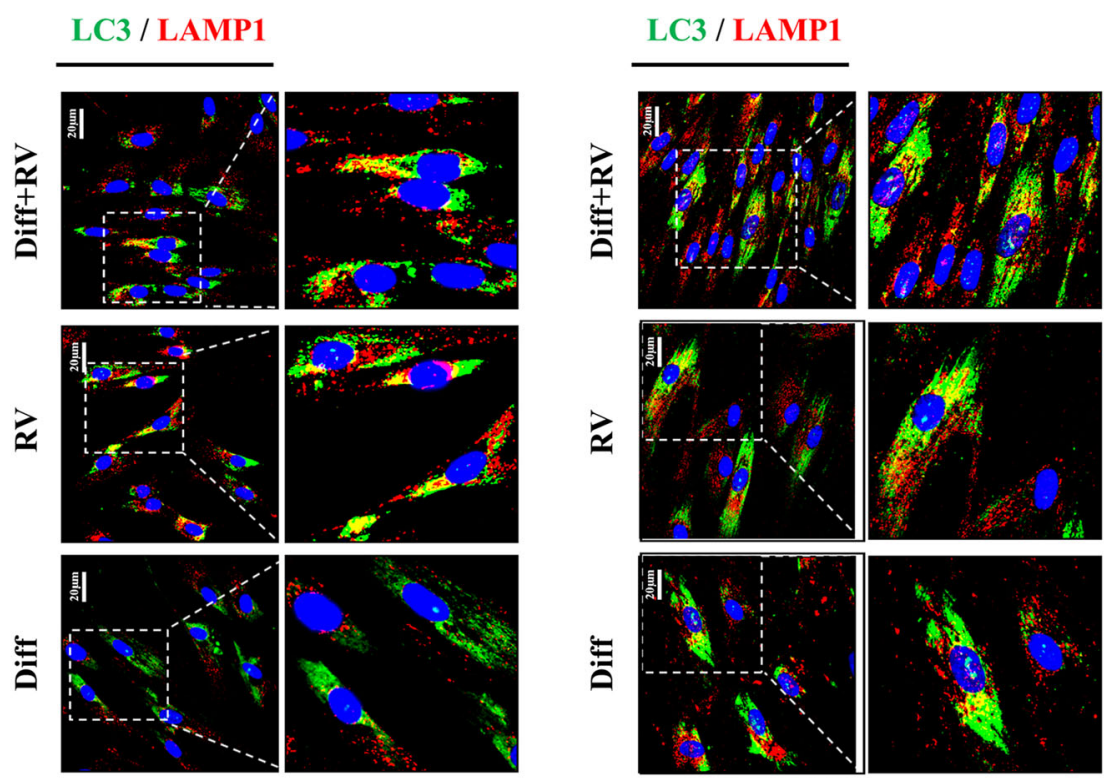

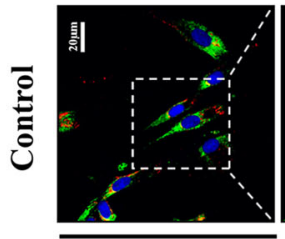

1 day

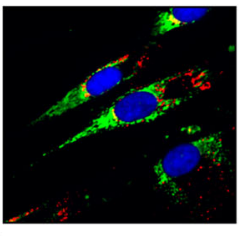

LC3/LAMP1 1 Day $\begin{aligned} & p \text {-value } \\ & * * p<0.01\end{aligned}$

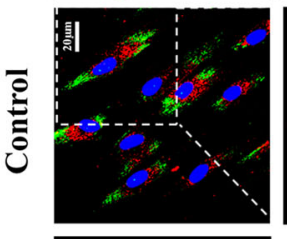

21 days
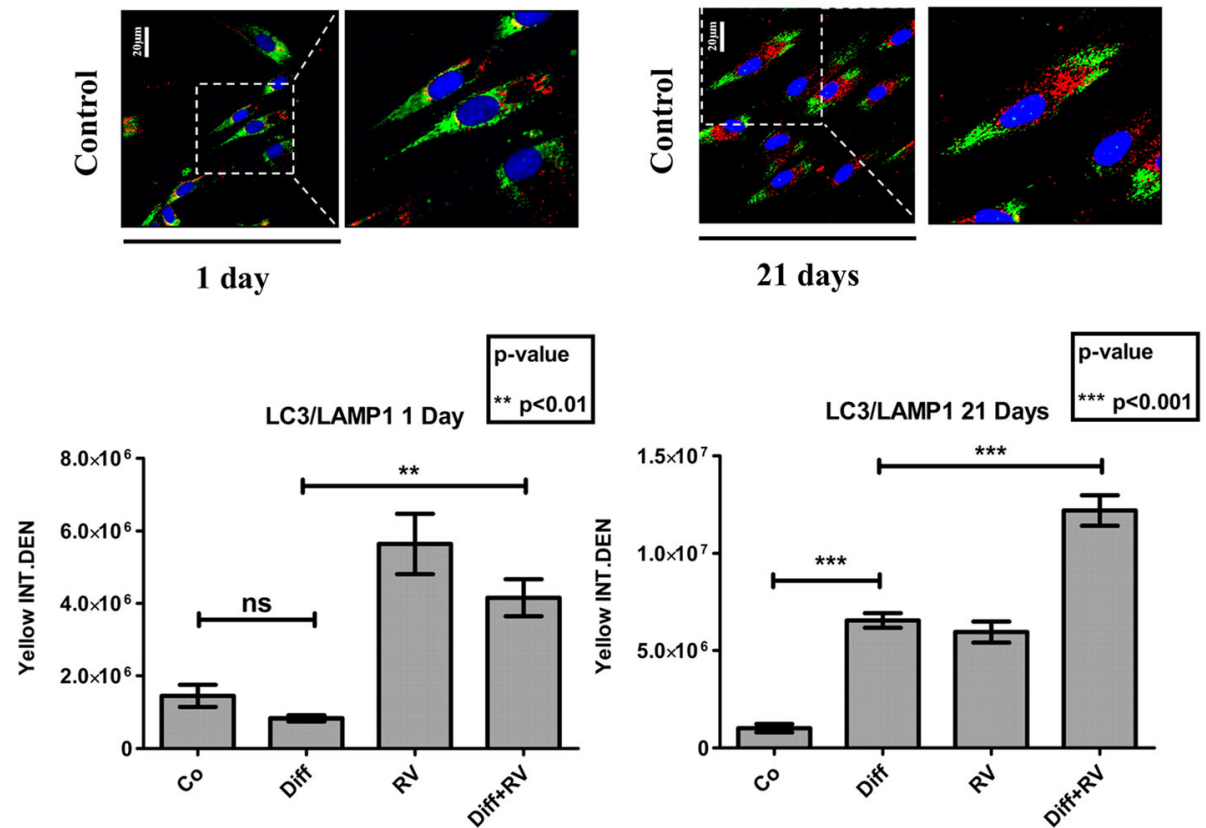

Fig. 6 Osteoblastic differentiation of Human Gingival Mesenchymal Stem Cells associates with induction of autophagy. HGMSCs were plated on sterile coverslips, let adhere and cultured for 1 to 21 days in control medium or in differentiation medium (Diff) supplemented or not with $1 \mu \mathrm{M}$ resveratrol (RV). At the end, the coverslips were fixed and processed for immunofluorescence staining of the autophagy markers LC3 (marker of autophagosomes) and LAMP1 (marker of lysosomes). Fluorescence staining was quantified with the ImageJ software. Integrated fluorescence intensity of co-labeled area (yellow) was calculated and reported in histograms

factors (Fig. 7). It is to be noted that by day 21, when the culture reached confluency and osteoblastic differentiation almost reached completion, the AMPK-BECLIN-1 pathway was switched off (Fig. 7).

\section{Inhibition of BECLIN-1-depedent autophagy impairs} osteogenic differentiation of HGMSCs by resveratrol Finally, we investigated whether autophagy was actively involved in the differentiation process or it was just an accompanying epiphenomenon. To this end, we monitored the occurrence of osteogenic differentiation in HGMSCs cultivated in the presence of spautin-1, a potent inhibitor of autophagy that promotes the proteasome-mediated degradation of BECLIN-1 [38]. We first determined the appropriate concentration of spautin-1 that could inhibit chronically (for 21 days) autophagy with no toxic side effect on HGMSCs cell viability (data not shown). $5 \mu \mathrm{M}$ Spautin-1 effectively depleted the cell 


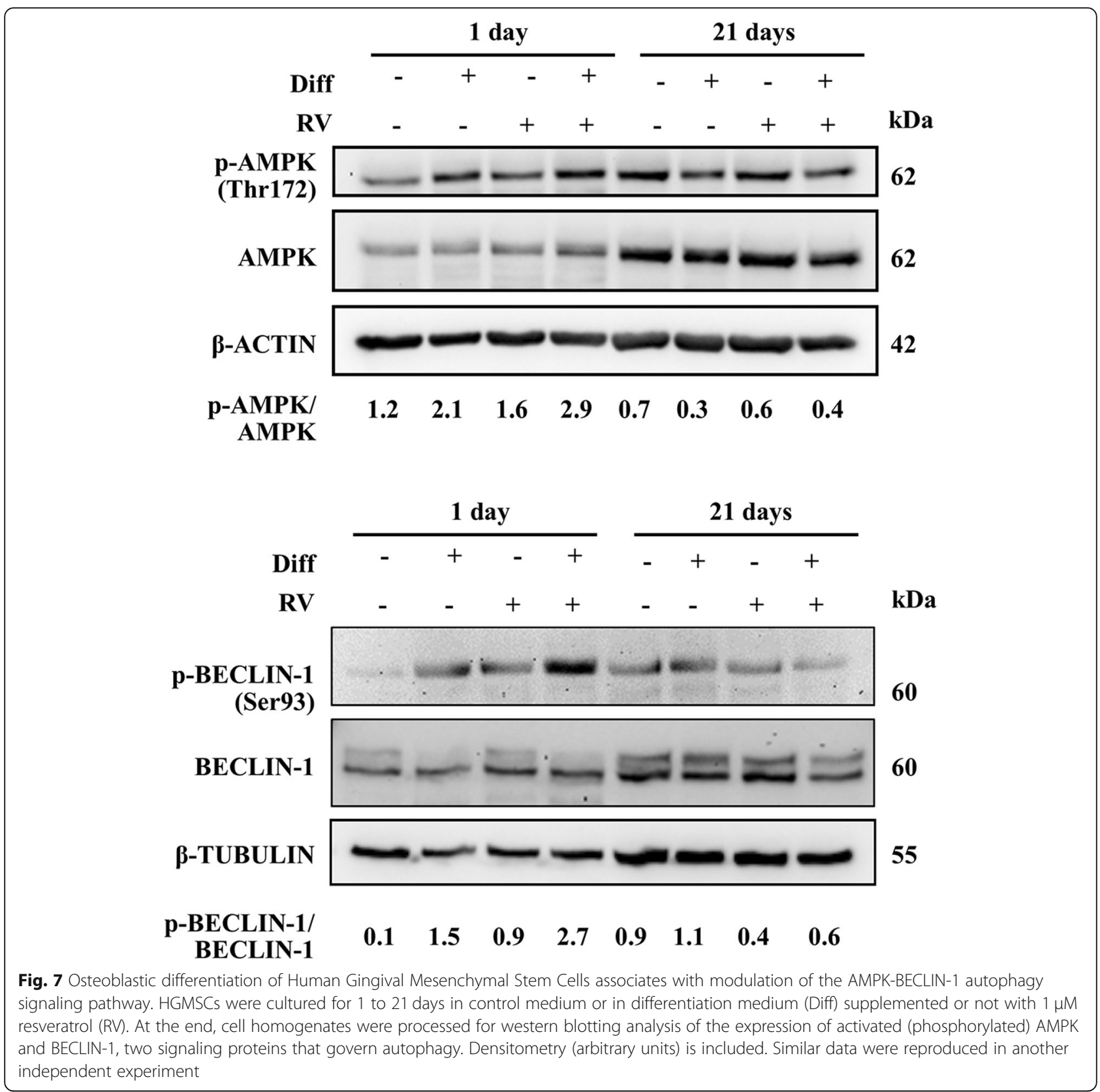

of BECLIN-1 (Fig. 8a), resulting in a strong inhibition of autophagy as shown by the impaired conversion of LC3I into LC3-II (Fig. 8b). This was further confirmed by the lack of interaction between BECLIN-1 and Vps34 (aka PI3KC3) in the cells cultivated in RV-supplemented differentiation medium in the presence of spautin-1, as shown by immunofluorescence co-staining (Fig. 8c). Next, we searched for the mechanistic link between autophagy and osteogenic differentiation. The chronic incubation in differentiation medium supplemented with $\mathrm{RV}$ led to the synthesis and accumulation of OCN in the cells with upregulated autophagy, as indicated by the presence of LC3-positive dots (Fig. 9a). However, in the parallel cultures co-treated with spautin-1 the number of LC3-positive dots per cell was greatly reduced to the level in controls and the $\mathrm{OCN}$ staining was faintly visible (Fig. 9a). Similarly, intense fluorescent staining of $\mathrm{OCN}$ and COL1A1 was apparent in the cells cultivated in RVsupplemented differentiation medium, while it was no apparent in the parallel culture co-treated with Sp-1 (Fig. $9 \mathrm{~b})$. From a functional point of view, spautin-1 inhibition of autophagy resulted in impaired mineralization of the extracellular matrix, as indicated by the lack of Alizarin Red-positive deposits of calcium (Fig. 9c). Additionally, western blotting of RUNX2, COL1A1, OPN and OCN showed that the expression of these 


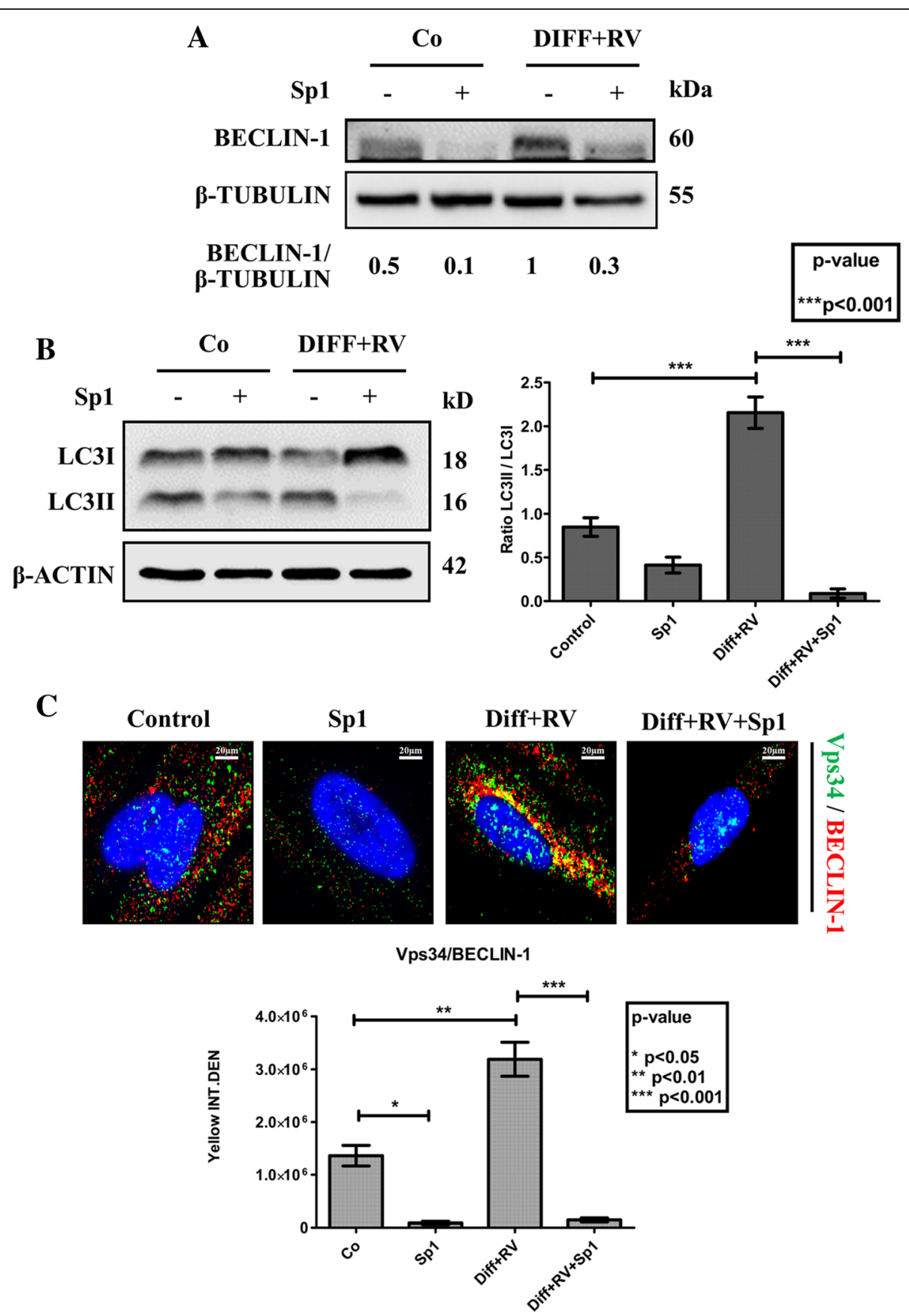

Fig. 8 Spautin-1 abrogates induction of BECLIN-1-dependent autophagy in Human Gingival Mesenchymal Stem Cells cultivated in osteoblastic differentiation condition. HGMSCs were cultured for 21 days in control medium or in differentiation medium supplemented with $1 \mu \mathrm{M}$ resveratrol (Diff + RV) in the absence or in the presence of spautin-1 (Sp1). At the end, cell homogenates were processed for western blotting analysis of the expression of $\mathbf{a}$ BECLIN-1 (target of spautin-1) and of $\mathbf{b}$ LC3 (marker of autophagosome). Densitometry (arbitrary units) of the specific bands is included. Data were reproduced in three independent experiments. The ratio LC3-II/LC3-I is assumed as an index of autophagosome and autolysosome accumulation in the cell. c HGMSCs were plated on sterile coverslips, let adhere and cultured for 21 days in control medium or in differentiation medium supplemented with $1 \mu \mathrm{M}$ resveratrol (Diff + RV) in the absence or the presence of spautin-1 (Sp1). At the end, the coverslips were fixed and processed for immunofluorescence staining of the autophagy interactome markers Vps34 (PI3KC3) and BECLIN-1. Fluorescence staining was quantified with the ImageJ software. Integrated fluorescence intensity of co-labeled area (yellow) was calculated and reported in histograms. Data from three coverslips per condition reproduced in three separate experiments 


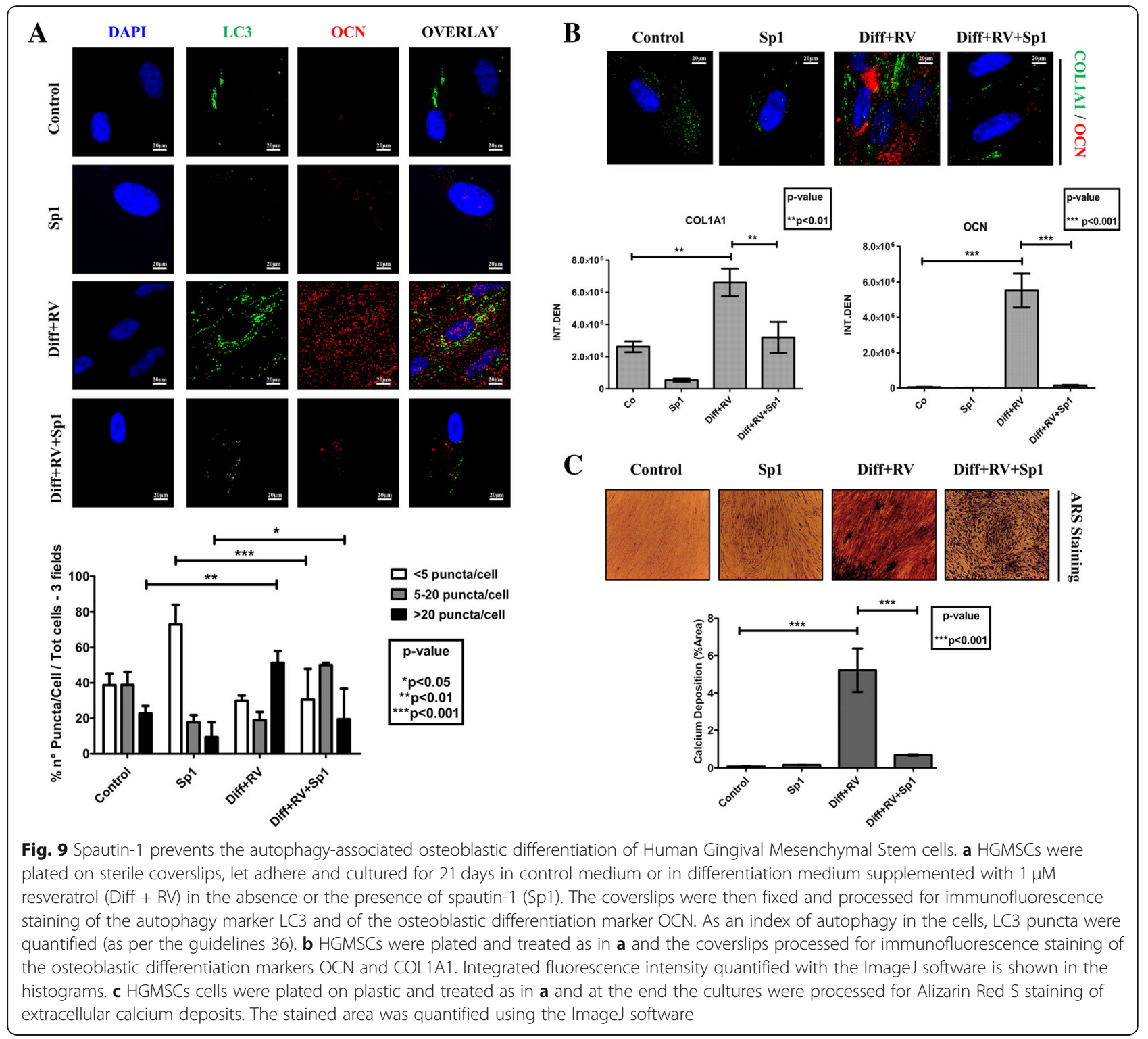

markers of osteogenic differentiation was completely prevented in the cultures exposed to Sp- 1 despite the concomitant presence in the medium of $\mathrm{RV}$ and osteogenic inductive factors (Fig. 10). From these data we may conclude that autophagy is functionally linked to osteogenic differentiation of HGMSCs.

\section{Discussion}

Autophagy is the major pathway for the cellular bulk degradation associated with the remodeling of cellular structures during differentiation of MSCs [23, 24]. During cellular differentiation, the autophagy pathway is finely tuned to meet the metabolic needs associated with the morpho-functional changes [22]. Two principal signaling pathways converging on the ULK1 complex control autophagy: the mTORC1 pathway, with inhibitory function, and the AMPK pathway, with activating function [39]. The mTORC1 pathway is positively triggered by growth factors and availability of nutrients, the AMPK pathway is activated when there is a lack of ATP production because of lack of nutrients or mitochondrial poisoning [40]. The AMPK-ULK1 pathway was shown to positively regulate autophagydependent mitochondrial homeostasis in embryonic stem cells, contributing to stemness properties [41]. Consistently, autophagy plays a role in maintaining the stemness properties and is modulated during stem cell differentiation [42]. In this work, we analyzed the contribution of autophagy in the osteoblastic differentiation of HGMSCs induced by RV or the osteoblastic inductive factors dexamethasone, $\beta$-glycerophosphate and ascorbic acid or their combination. We 


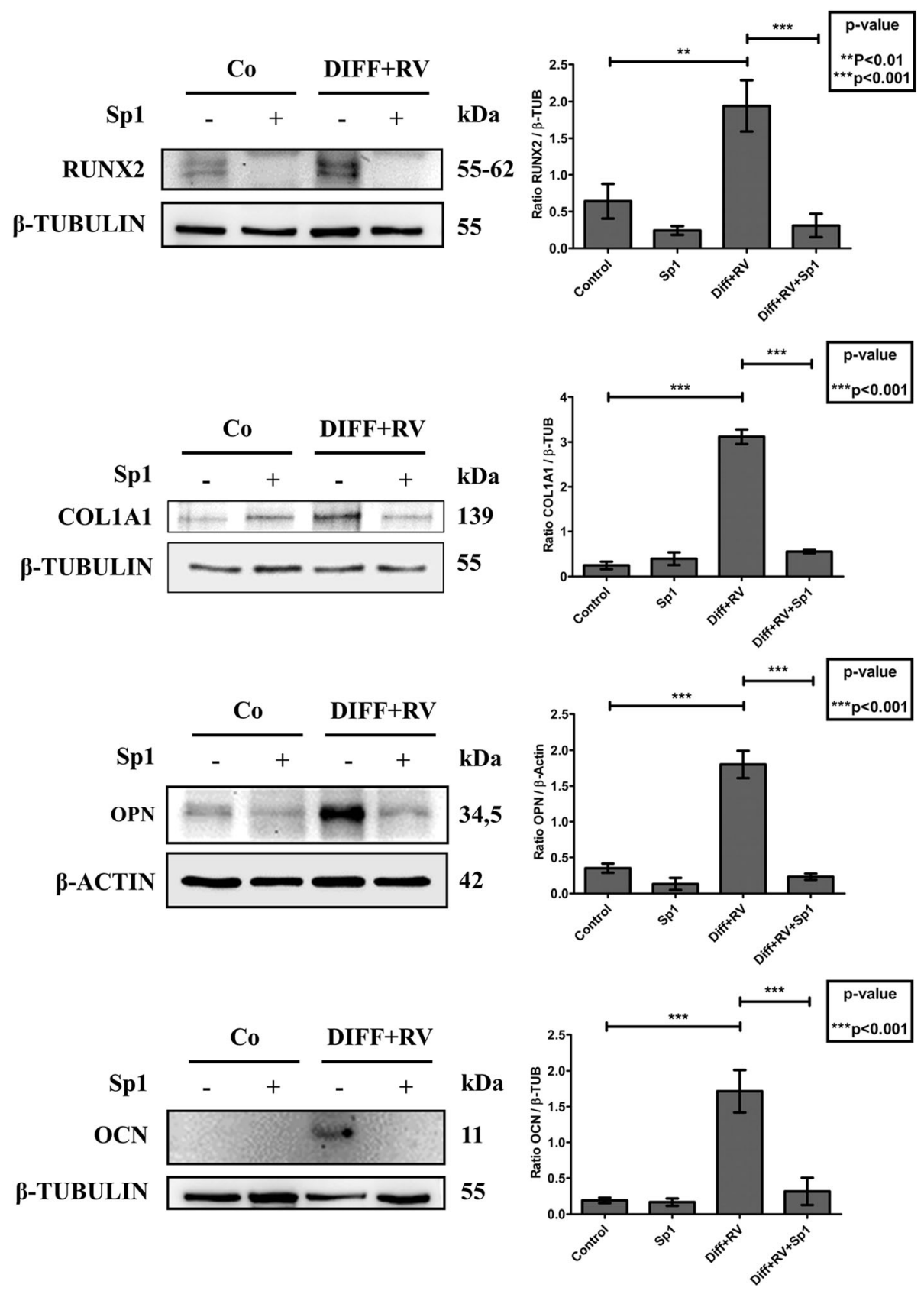

Fig. 10 Spautin-1 prevents the expression of osteoblastic differentiation markers in Human Gingival Mesenchymal Stem cells. HGMSCs were cultured for 21 days in control medium or in differentiation medium supplemented with $1 \mu \mathrm{M}$ resveratrol (Diff + RV) in the absence or in the presence of spautin-1 (Sp1). At the end, cell homogenates were processed for western blotting analysis of the expression of the osteoblastic transcription factor RUNX-2 and of the osteogenic differentiation markers COL1A1, OPN and OCN. Densitometry of the specific bands (average \pm S.D.) of three independent experiments is shown in the histograms

demonstrate that RV induces the osteoblastic differentiation of HGMSCs when used at $1 \mu \mathrm{M}$, while it is toxic at concentrations above $10 \mu \mathrm{M}$. Our results are in agreement with similar studies conducted on human bone-derived MSCs [17] and human embryonic stem cells [18]. Compared to the osteogenic inductive factors, RV elicited a less pronounced differentiation by day 21. It is likely that prolonging the incubation with RV would eventually attain a full osteoblastic differentiation. RV induced the expression and promoted the nuclear translocation of the osteogenic transcription factor RUNX2. Remarkably, RV synergized with the osteogenic inductive factors accelerating the osteoblastic differentiation of HGMSCs, as indicated by 
anticipation and increased mineralization of the extracellular matrix. Signs of osteoblastic differentiation such as OCN synthesis and extracellular calcium deposits became detectable after 7 days of culture. Osteoblastic differentiation of HGMSCs was strictly dependent on BECLIN-1 dependent autophagy, as demonstrated by the observation that it was prevented by spautin-1 induced depletion of BECLIN-1 and consequent inhibition of autophagy. It is likely that RV accelerated the osteoblastic differentiation of HGMSCs cultivated in the osteogenic differentiation medium because of its strong stimulation of autophagy. RV has been shown to induce autophagy in mouse embryonic stem cells via activation of the AMPK/ULK1 pathway, and this correlated with enhanced pluripotency of the cells [37]. RV mimics a situation of energy restriction and activates the AMPK pathway regardless of the presence of nutrients, leading to activation of autophagy [27]. Activation of AMPK bypasses the block by mTORC1 and triggers autophagy through direct activating phosphorylation of ULK1 and of BECLIN-1 [43, 44]. Under metabolic stress conditions, the parallel activation of mTOR and of AMPK allows the coordinated and contemporary protein degradation and protein synthesis processes, with the former providing the amino acids needed for the latter [45]. We observed that AMPK was transitorily activated in HGMSCs undergoing cell differentiation and it was down-regulated when osteoblastic differentiation was achieved. This same pattern was paralleled by phosphorylated Ser93 BECLIN-1, which is operated by AMPK [44]. Modulation of AMPK activation drives osteoblast differentiation: it is induced during early differentiation and its silencing or inhibition causes bone loss, yet its constitutive activation prevents full differentiation [46]. This modulation was paralleled by modulation of autophagy, suggesting that down-regulation of AMPK-dependent autophagy could favor glycolysis, which is necessary in the late stages of differentiation [46]. Interestingly, similar findings were reported in the myoblast to myotube differentiation of muscle satellite cells, which are regarded as stem-like cells [47]. Thus, down-regulation of the AMPK-BECLIN-1 pathway is consistent with the progressive downregulation of autophagy to basal levels once that full differentiation is achieved when it is no more requested the degradation of redundant or unwanted cell components.

\section{Conclusions}

In summary, here, we provide for the first time the evidence that RV and osteogenic inductive factors synergize to induce the osteoblastic differentiation of HGMSCs and that this process relies on modulation of autophagy. Human gingiva represents an abundant and easily accessible source of MSCs. The possibility of inducing the differentiation of HGMSCs in an osteogenic sense in vitro can be translated into the regenerative cell therapy of maxillary / mandibular bone defects $[5,6,48]$. Inductive factors such as RV and autophagy modulators can be incorporated into scaffold nanostructures containing HGMSCs and be implanted in situ for repairing and reconstructive purposes) [49].

\section{Abbreviations \\ COL1A1: Collagen 1a1; HGMSC: Human gingival mesenchymal stem cell; OCN: Osteocalcin; OPN: Osteopontin; RV: Resveratrol; Sp1: Spautin-1}

\section{Acknowledgements}

This research had the financial support of the Università del Piemonte Orientale. The Microscope fluorescence imaging facility was donated by Comoli, Ferrari \& SpA (Novara, Italy). C.V. was supported with a fellowship funded by the Associazione per la Ricerca Medica Ippocrate-Rhazi (Novara, |taly).

\section{Authors' contributions}

$\mathrm{Cl}$ and $\mathrm{CM}$ conceived and coordinated the study; $\mathrm{CV}$ and $\mathrm{Cl}$ designed the experiments; CG and BZ isolated and characterized the HGMSCs; CV, AF, ES and LV performed the experiments; CV and AF drafted the manuscript; $\mathrm{Cl}$ revised and finalized the manuscript. All authors read and approved the final manuscript.

\section{Author's information}

Chiara Vidoni received her PhD degree in Medical Sciences and Biotechnology at Università del Piemonte Orientale (Novara, Italy) in 2017. She performed her PhD studies under the mentorship of Prof. Ciro Isidoro in the Laboratory of Molecular Pathology. She completed her Master's degree in Medical Biotechnologies at Università del Piemonte Orientale in 2012. She received her Bachelor's degree in Biotechnologies at Università del Piemonte Orientale in 2009. From 2017, she is postdoctoral fellow in Prof. Isidoro's Laboratory. Her current research focused on the role and regulation of autophagy in neurodegenerative diseases, cancer and regenerative medicine. She has co-authored ten articles published in peer-reviewed journals. Alessandra Ferraresi is a post-doctoral fellow at Università del Piemonte Orientale in Prof. Isidoro's lab. She received her PhD in Medical Sciences and Biotechnology at Università del Piemonte Orientale (Novara, Italy) in 2019. She completed her Master's degree in Pharmaceutical Biotechnologies with honors at Alma Mater Studiorum-Università di Bologna in 2014. She received her Bachelor's degree in Biotechnologies at Università di Parma in 2011. Her current research focused on the role and regulation of autophagy in cancer, particularly in cancer cell migration and resistance to metabolic stress. She has co-authored nine articles published in peer-reviewed journals. Eleonora Secomandi is a PhD student in Medical Sciences and Biotechnology at Università del Piemonte Orientale (Novara, Italy), working under the mentorship of Prof. Ciro Isidoro in the Laboratory of Molecular Pathology. She completed the Master's degree in Medical Biotechnologies with honors at Università del Piemonte Orientale di Novara in 2018. She received her Bachelor's degree in Biological Sciences at Università del Piemonte Orientale in 2016. Her current research focused on cancer biology, protein synthesis and regulation of autophagy in cancer.

She has co-authored four articles published in peer-reviewed journals. Letizia Vallino is a master student in Biomedical and Biomolecular Biology at Università del Piemonte Orientale in Alessandria (Italy). In 2018 to present, she works in Laboratory of Molecular Patology under the supervision of Prof. Ciro Isidoro. She received her Bachelor's degree in Biology Sciences at Università del Piemonte Orientale in Vercelli (Italy) in 2017. Her current research focused on cancer biology, particularly cancer-related autophagy, cancer metabolism and epigenetic control. She has co-authored one article published in peer-reviewed journals.

Chiara Gardin is a post doc student working under the mentorship of Prof Barbara Zavan in the Laboratory of Tissue Engineering and Regenerative Medicine at Università of Ferrara (Ferrara, Italy). She completed her PhD working under the mentorship of Prof. Giorgio Valle in the laboratory of Molecular Sciences at University of Padova (Padova). She completed her 
master's degree in Biological Sciences with honors at University of Padova. Her current research focused on the role Mesenchymal stem cell as tool on tissue regeneration.

She has co-authored seven articles published in peer-reviewed journals. Barbara Zavan received her PhD on Tissue Engineering and Regenerative Medicine at University of Padova (Padova, Italy) and her doctoral degree (summa cum laude) in Biological Sciences from the University of Padova (Padova, Italy). Currently, he is Associate Professor of Medical Sciences Tecnology at the school of Medicine of University of Ferrara (Ferrara, Italy). He is Visiting Professor at the University of Murcia, Faculty of Medicine (Murcia, Spain). Her research seeks to understand how changes in stem cell activity impact tissue homeostasis and repair throughout life and to identify systemic molecules or surfaced modification are responsible for regulation of regenerative potential. She has a multidisciplinary research group focused on both high quality fundamental science and translation for human health. She has active collaborations with bioengineers, chemists and clinicians in order to study stem cell-niche interactions in vitro.

Carmen Mortellaro obtained the degree in Medicine and Surgery and the Specialization Diploma in Odontostomatology and Orthognathology from the University of Turin. She is currently Full Professor of Stomatological Diseases at the School of Medicine and Surgery of the University of Piemonte Orientale and Director of the Orthodontic-Surgical Operative Unit for the diagnosis and therapy of craniofacial skeletal alterations and oral surgery. She teaches diseases of the oral cavity, oral surgery, dental materials, orthodontics, pedodontics, clinical semeiotics of the craniofacial district, exodontic surgery and anatomy. She is President Anthec (Academy of Non Transfusional Hemo-Components). She has authored 250 publications in scientific journals and international conference proceedings and peer reviewer of some international journals, including Indian Journal of Dentistry and Journal of Oral Pathology \& Medicine. She is a member of the Editorial Board of the Craniofacial Journal.

Ciro Isidoro (www.isidorolab.com) received his doctoral degree (summa cum laude) in Biological Sciences from the University of Torino (Italy) and his doctoral degree (summa cum laude) in Medicine and Surgery from the University of Piemonte Orientale (Novara, Italy). Currently, he is Professor of Pathology and of Experimental Oncology at the school of Medicine of University of Piemonte Orientale (Novara, Italy). He is Visiting Professor at the Department of Cell Biology of the University of Oklahoma Collage of Medicine (Oklahoma City, United States). He is Professeur Honoraire at the Faculté de Medecine et de Phamacie de l'Université de Franche-Comté (Besancon, France). He is member of the scientific board of the "Centre for Integrative Cancer Research" of the Georgia Tech Institute, University of Georgia (Atlanta, US). He is Co-Editor in Chief of the J. of Traditional and Complementary Medicine, and Associate Editor of Autophagy, BMC Cancer, Molecular Carcinogenesis, J. of Ovarian Research, Genes and Cancers, J. of Molecular Signaling, and other journals. His fields of expertise include lysosome biogenesis and function, autophagy regulation in cancer and in neurodegenerative diseases, cell death pathways, mechanisms of action of natural products, epigenetic regulation of autophagy and of cell death.

\section{Funding}

This research had the financial support of the Università del Piemonte Orientale.

\section{Availability of data and materials}

All data generated or analysed during this study are included in this research article.

\section{Ethics approval and consent to participate}

Include a statement on ethics approval and consent.

\section{Consent for publication}

Not applicable.

\section{Competing interests}

The authors declare that they have no competing interests.

\section{Author details}

'Laboratory of Molecular Pathology, Department of Health Sciences, Università del Piemonte Orientale "A. Avogadro", Via P. Solaroli 17, 28100 Novara, Italy. " Maria Cecilia Hospital, GVM Care \& Research, via Corriera 1,
48033, Cotignola, Ravenna, Italy. ${ }^{3}$ Medical Sciences Department, University of Ferrara, Via Fossato di Mortara, 70 Ferrara, Italy. ${ }^{4}$ Oral Surgery Unit, Department of Medical Science, Università del Piemonte Orientale "A Avogadro", Novara, Italy.

Received: 16 May 2019 Accepted: 5 August 2019

Published online: 19 August 2019

\section{References}

1. Griffin M, lqual SA, Bayat A. Exploring the application of mesenchymal stem cells in bone repair and regeneration. J Bone Joint Surg Br. 2011;93(4):427-34. https:/ doi.org/10.1302/0301-620X.93B4.25249 Review. PubMed PMID: 2146447.

2. Pagni G, Kaigler D, Rasperini G, Avila-Ortiz G, Bartel R, Giannobile WV. Bone repair cells for craniofacial regeneration. Adv Drug Deliv Rev. 2012;64(12): 1310-9. https://doi.org/10.1016/j.addr.2012.03.005 Epub 2012 Mar 10. Review. PubMed PMID: 22433781; PubMed Central PMCID: PMC3383887.

3. Grässel S, Lorenz J. Tissue-engineering strategies to repair chondral and osteochondral tissue in osteoarthritis: use of mesenchymal stem cells. Curr Rheumatol Rep. 2014;16(10):452. https://doi.org/10.1007/s11926-014-0452-5 Review. PubMed PMID: 25182680; PubMed Central PMCID: PMC4182613.

4. Wang F, Yu M, Yan X, Wen Y, Zeng Q, Yue W, Yang P, Pei X. Gingiva-derived mesenchymal stem cell-mediated therapeutic approach for bone tissue regeneration. Stem Cells Dev. 2011;20(12):2093-102. https://doi.org/10.1089/ scd.2010.0523 Epub 2011 Apr 27. PubMed PMID: 21361847.

5. Zhao N, Wu Z, Qin L, Guo Z, Li D. Characteristics and tissue regeneration properties of gingiva-derived mesenchymal stem cells. Crit Rev Eukaryot Gene Expr. 2015;25(2):135-44 Review. PubMed PMID: 26080607.

6. Fawzy El-Sayed KM, Dörfer CE. Gingival mesenchymal stem/progenitor cells: a unique tissue engineering gem. Stem Cells Int. 2016;2016:7154327. https:// doi.org/10.1155/2016/7154327 Epub 2016 May 29. Review. PubMed PMID: 27313628; PubMed Central PMCID: PMC4903147.

7. Xu D, Xu L, Zhou C, Lee WY, Wu T, Cui L, Li G. Salvianolic acid B promotes osteogenesis of human mesenchymal stem cells through activating ERK signaling pathway. Int J Biochem Cell Biol. 2014;51:1-9. https://doi.org/10.1 016/j.biocel.2014.03.005 Epub 2014 Mar 19. PubMed PMID: 24657587.

8. Du L, Yang P, Ge S. Isolation and characterization of human gingiva-derived mesenchymal stem cells using limiting dilution method. J Dent Sci. 2016; 11(3):304-14. https://doi.org/10.1016/j.jds.2016.03.010 Epub 2016 May 6. PubMed PMID: 30894989; PubMed Central PMCID: PMC6395297.

9. Chen Y, Liu H. The differentiation potential of gingival mesenchymal stem cells induced by apical tooth germ cell-conditioned medium. Mol Med Rep. 2016;14(4):3565-72. https://doi.org/10.3892/mmr.2016.5726 Epub 2016 Sep 6. PubMed PMID: 27600358; PubMed Central PMCID: PMC5042793.

10. Ha DH, Yong CS, Kim JO, Jeong JH, Park JB. Effects of tacrolimus on morphology, proliferation and differentiation of mesenchymal stem cells derived from gingiva tissue. Mol Med Rep. 2016;14(1):69-76. https://doi. org/10.3892/mmr.2016.5217 Epub 2016 May 6. PubMed PMID: 27177273; PubMed Central PMCID: PMC4918528.

11. Murugan Girija D, Y Ranga Rao S, Kalachaveedu M, Subbarayan R. Osteogenic differentiation of human gingival mesenchymal stem cells by Aristolochia bracteolata supplementation through enhanced Runx2 expression. J Cell Physiol. 2017;232(7):1591-5. https://doi.org/10.1002/jcp.25 835 Epub 2017 Feb 21. PubMed PMID: 28150858.

12. Mobasheri A, Shakibaei M. Osteogenic effects of resveratrol in vitro: potential for the prevention and treatment of osteoporosis. Ann N Y Acad Sci. 2013;1290:59-66. https://doi.org/10.1111/nyas.12145 Review. PubMed PMID: 23855466

13. Murgia D, Mauceri R, Campisi G, De Caro V. Advance on Resveratrol Application in Bone Regeneration: Progress and Perspectives for Use in Oral and Maxillofacial Surgery. Biomolecules. 2019;9(3). https://doi.org/10.3390/ biom9030094 Review. PubMed PMID: 30857241; PubMed Central PMCID: PMC6468380

14. Rafe T, Shawon PA, Salem L, Chowdhury NI, Kabir F, Zahur SMB, Akther R, Noor HB, Mohib MM, Sagor MAT. Preventive role of Resveratrol against inflammatory cytokines and related diseases. Curr Pharm Des. 2019. https:// doi.org/10.2174/1381612825666190410153307 [Epub ahead of print] PubMed PMID: 30968773.

15. He X, Andersson G, Lindgren U, Li Y. Resveratrol prevents RANKL-induced osteoclast differentiation of murine osteoclast progenitor RAW 264.7 cells through inhibition of ROS production. Biochem Biophys Res Commun. 
2010;401(3):356-62. https://doi.org/10.1016/j.bbrc.2010.09.053 Epub 2010 Sep 17. PubMed PMID:20851107.

16. Matsuda Y, Minagawa T, Okui T, Yamazaki K. Resveratrol suppresses the alveolar bone resorption induced by artificial trauma from occlusion in mice. Oral Dis. 2018;24(3):412-21. https://doi.org/10.1111/odi.12785 Epub 2017 Oct 23. PubMed PMID:28944599.

17. Dai Z, Li Y, Quarles LD, Song T, Pan W, Zhou H, Xiao Z. Resveratrol enhances proliferation and osteoblastic differentiation in human mesenchymal stem cells via ER-dependent ERK1/2 activation. Phytomedicine. 2007;14(12):80614 Epub 2007 Aug 8. PubMed PMID: 17689939.

18. Tseng PC, Hou SM, Chen RJ, Peng HW, Hsieh CF, Kuo ML, Yen ML. Resveratrol promotes osteogenesis of human mesenchymal stem cells by upregulating RUNX2 gene expression via the SIRT1/FOXO3A axis. J Bone Miner Res. 2011;26(10):2552-63. https://doi.org/10.1002/jbmr.460 PubMed PMID: 21713995.

19. Shakibaei M, Shayan P, Busch F, Aldinger C, Buhrmann C, Lueders C, Mobasheri A. Resveratrol mediated modulation of Sirt-1/Runx2 promotes osteogenic differentiation of mesenchymal stem cells: potential role of Runx2 deacetylation. PLoS One. 2012;7(4):e35712. https://doi.org/10.1371/ journal.pone.0035712 Epub 2012 Apr 23. PubMed PMID: 22539994; PubMed Central PMCID: PMC3335081.

20. Casarin RC, Casati MZ, Pimentel SP, Cirano FR, Algayer M, Pires PR, Ghiraldini B, Duarte PM, Ribeiro FV. Resveratrol improves bone repair by modulation of bone morphogenetic proteins and osteopontin gene expression in rats. Int J Oral Maxillofac Surg. 2014;43(7):900-6. https://doi.org/10.1016/j.jom.2 014.01.009 Epub 2014 Feb 13. PubMed PMID: 24530035.

21. Ornstrup MJ, Harsløf T, Sørensen L, Stenkjær L, Langdahl BL, Pedersen SB. Resveratrol increases osteoblast differentiation in vitro independently of inflammation. Calcif Tissue Int. 2016;99(2):155-63. https://doi.org/10.1007/ s00223-016-0130-x Epub 2016 Mar 21. PubMed PMID: 27000750

22. Fortini P, lorio E, Dogliotti E, Isidoro C. Coordinated metabolic changes and modulation of autophagy during Myogenesis. Front Physiol. 2016;7:237. https://doi.org/10.3389/fphys.2016.00237 eCollection 2016. PubMed PMID: 27378945: PubMed Central PMCID: PMC4909729.

23. Wang $S, X i a P$, Rehm M, Fan Z. Autophagy and cell reprogramming. Cell Mol Life Sci. 2015;72(9):1699-713. https://doi.org/10.1007/s00018-014-1829-3 Epub 2015 Jan 9. Review. PubMed PMID: 25572296.

24. Boya $\mathrm{P}$, Codogno $\mathrm{P}$, Rodriguez-Muela N. Autophagy in stem cells: repair, remodelling and metabolic reprogramming. Development. 2018;145(4). https://doi.org/10.1242/dev.146506 Review. PubMed PMID: 29483129.

25. Dikic I, Elazar Z. Mechanism and medical implications of mammalian autophagy. Nat Rev Mol Cell Biol. 2018;19(6):349-64. https://doi.org/10.1038/ s41580-018-0003-4 Review. PubMed PMID: 29618831

26. Jaber FA, Khan NM, Ansari MY, Al-Adlaan AA, Hussein NJ, Safadi FF. Autophagy plays an essential role in bone homeostasis. J Cell Physiol. 2019; 234(8):12105-15. https://doi.org/10.1002/jcp.27071 Epub 2019 Feb 28. Review. PubMed PMID: 30820954

27. Ferraresi A, Titone R, Follo C, Castiglioni A, Chiorino G, Dhanasekaran DN, Isidoro C. The protein restriction mimetic resveratrol is an autophagy inducer stronger than amino acid starvation in ovarian cancer cells. Mol Carcinog. 2017;56(12):2681-91. https://doi.org/10.1002/mc.22711 Epub 2017 Sep 7. PubMed PMID: 28856729.

28. Ge S, Mrozik KM, Menicanin D, Gronthos S, Bartold PM. Isolation and characterization of mesenchymal stem cell-like cells from healthy and inflamed gingival tissue: potential use for clinical therapy. Regen Med. 2012; 7(6):819-32. https://doi.org/10.2217/rme.12.61 PubMed PMID: 23164082.

29. Gardin C, Ferroni L, Bellin G, Rubini G, Barosio S, Zavan B. Therapeutic Potential of Autologous Adipose-Derived Stem Cells for the Treatment of Liver Disease. Int J Mol Sci. 2018;19(12). https://doi.org/10.3390/ijms19124 064 PubMed PMID: 30558283; PubMed Central PMCID: PMC6321531.

30. Chevallier N, Anagnostou F, Zilber S, Bodivit G, Maurin S, Barrault A, Bierling P, Hernigou P, Layrolle P, Rouard H. Osteoblastic differentiation of human mesenchymal stem cells with platelet lysate. Biomaterials. 2010;31(2):270-8. https://doi.org/10.1016/j.biomaterials.2009.09.043 Epub 2009 Sep 26. PubMed PMID: 19783038.

31. Puchtler $\mathrm{H}$, Meloan SN, Terry MS. On the history and mechanism of alizarin and alizarin red S stains for calcium. J Histochem Cytochem. 1969;17(2):11024 PubMed PMID: 4179464.

32. Dominici M, Le Blanc K, Mueller I, Slaper-Cortenbach I, Marini F, Krause D, Deans R, Keating A, Prockop DJ, Horwitz E. Minimal criteria for defining multipotent mesenchymal stromal cells. The International Society for
Cellular Therapy position statement. Cytotherapy. 2006;8(4):315-7 PubMed PMID: 16923606

33. Long MW. Osteogenesis and bone-marrow-derived cells. Blood Cells Mol Dis. 2001:27(3):677-90 Review. PubMed PMID: 11482883.

34. Ducy P, Karsenty G. Two distinct osteoblast-specific cis-acting elements control expression of a mouse osteocalcin gene. Mol Cell Biol. 1995:15(4): 1858-69 PubMed PMID: 7891679; PubMed Central PMCID: PMC230411.

35. Lee KE, Seymen F, Ko J, Yildirim M, Tuna EB, Gencay K, Kim JW. RUNX2 mutations in cleidocranial dysplasia. Genet Mol Res. 2013;12(4):4567-74. https://doi.org/10.4238/2013.October.15.5 PubMed PMID: 24222232.

36. Klionsky DJ, Abdelmohsen K, Abe A, Abedin MJ, Abeliovich H, Acevedo Arozena $A$, et al. Guidelines for the use and interpretation of assays for monitoring autophagy (3rd edition). Autophagy. 2016;12(1):1-222 PubMed PMID: 26799652.

37. Suvorova II, Knyazeva AR, Petukhov AV, Aksenov ND, Pospelov VA. Resveratrol enhances pluripotency of mouse embryonic stem cells by activating AMPK/Ulk1 pathway. Cell Death Dis. 2019;5:61. https://doi.org/1 0.1038/s41420-019-0137-y eCollection 2019. PubMed PMID: 30729040; PubMed Central PMCID: PMC6361884.

38. Liu J, Xia H, Kim M, Xu L, Li Y, Zhang L, Cai Y, Norberg HV, Zhang T, Furuya T, Jin M, Zhu Z, Wang H, Yu J, Li Y, Hao Y, Choi A, Ke H, Ma D, Yuan J. Beclin1 controls the levels of p53 by regulating the deubiquitination activity of USP10 and USP13. Cell. 2011;147(1):223-34. https://doi.org/10.1016/j.cell.2 011.08.037 PubMed PMID: 21962518; PubMed Central PMCID: PMC3441147.

39. Kim J, Kundu M, Viollet B, Guan KL. AMPK and mTOR regulate autophagy through direct phosphorylation of Ulk1. Nat Cell Biol. 2011;13(2):132-41. https://doi.org/10.1038/ncb2152 Epub 2011 Jan 23. PubMed PMID: 21258367; PubMed Central PMCID: PMC3987946.

40. Ravikumar B, Sarkar S, Davies JE, Futter M, Garcia-Arencibia M, GreenThompson ZW, Jimenez-Sanchez M, Korolchuk VI, Lichtenberg M, Luo S, Massey DC, Menzies FM, Moreau K, Narayanan U, Renna M, Siddiqi FH, Underwood BR, Winslow AR, Rubinsztein DC. Regulation of mammalian autophagy in physiology and pathophysiology. Physiol Rev. 2010;90(4): 1383-435. https://doi.org/10.1152/physrev.00030.2009 Review. PubMed PMID: 20959619

41. Gong J, Gu H, Zhao L, Wang L, Liu P, Wang F, Xu H, Zhao T. Phosphorylation of ULK1 by AMPK is essential for mouse embryonic stem cell self-renewal and pluripotency. Cell Death Dis. 2018;9(2):38. https://doi. org/10.1038/s41419-017-0054-z PubMed PMID: 29348566; PubMed Central PMCID: PMC5833692.

42. Sotthibundhu A, Promjuntuek W, Liu M, Shen S, Noisa P. Roles of autophagy in controlling stem cell identity: a perspective of self-renewal and differentiation. Cell Tissue Res. 2018;374(2):205-16. https://doi.org/10.1 007/s00441-018-2829-7 Epub 2018 Apr 25. Review. PubMed PMID: 29696372.

43. Egan DF, Shackelford DB, Mihaylova MM, Gelino S, Kohnz RA, Mair W, Vasquez DS, Joshi A, Gwinn DM, Taylor R, Asara JM, Fitzpatrick J, Dillin A, Viollet B, Kundu M, Hansen M, Shaw RJ. Phosphorylation of ULK1 (hATG1) by AMP-activated protein kinase connects energy sensing to mitophagy. Science. 2011;331(6016):456-61. https://doi.org/10.1126/science.1196371 Epub 2010 Dec 23. PubMed PMID: 21205641; PubMed Central PMCID: PMC3030664.

44. Kim J, Kim YC, Fang C, Russell RC, Kim JH, Fan W, Liu R, Zhong Q, Guan KL. Differential regulation of distinct Vps34 complexes by AMPK in nutrient stress and autophagy. Cell. 2013;152(1-2):290-303. https://doi.org/10.1016/j. cell.2012.12.016 PubMed PMID: 23332761; PubMed Central PMCID: PMC3587159.

45. Follo C, Vidoni C, Morani F, Ferraresi A, Seca C, Isidoro C. Amino acid response by Halofuginone in Cancer cells triggers autophagy through proteasome degradation of mTOR. Cell Commun Signal. 2019;17(1):39. https://doi.org/10.1186/s12964-019-0354-2 PubMed PMID: 31046771; PubMed Central PMCID: PMC6498594.

46. Xi G, Rosen CJ, Clemmons DR. IGF-I and IGFBP-2 stimulate AMPK activation and autophagy, which are required for osteoblast differentiation. Endocrinology. 2016;157(1):268-81. https://doi.org/10.1210/en.2015-1690 Epub 2015 Nov 10. PubMed PMID: 26556533; PubMed Central PMCID: PMC4701891.

47. Fortini $P$, Ferretti $C$, lorio $E$, Cagnin $M$, Garribba L, Pietraforte D, Falchi M, Pascucci B, Baccarini S, Morani F, Phadngam S, De Luca G, Isidoro C, Dogliotti $E$. The fine tuning of metabolism, autophagy and differentiation during in vitro myogenesis. Cell Death Dis. 2016;7:e2168. https://doi.org/10.1 038/cddis.2016.50 PubMed PMID: 27031965; PubMed Central PMCID: PMC4823951. 
48. Shakoori P, Zhang Q, Le AD. Applications of mesenchymal stem cells in Oral and craniofacial regeneration. Oral Maxillofac Surg Clin North Am. 2017; 29(1):19-25. https://doi.org/10.1016/j.coms.2016.08.009 Review. PubMed PMID: 27890225.

49. Kamath MS, Ahmed SS, Dhanasekaran M, Santosh SW. Polycaprolactone scaffold engineered for sustained release of resveratrol: therapeutic enhancement in bone tissue engineering. Int I Nanomedicine. 2014;9:18395. https://doi.org/10.2147/JN.S49460 Epub 2013 Dec 23. PubMed PMID: 24399875; PubMed Central PMCID: PMC3875521

\section{Publisher's Note}

Springer Nature remains neutral with regard to jurisdictional claims in published maps and institutional affiliations.

Ready to submit your research? Choose BMC and benefit from:

- fast, convenient online submission

- thorough peer review by experienced researchers in your field

- rapid publication on acceptance

- support for research data, including large and complex data types

- gold Open Access which fosters wider collaboration and increased citations

- maximum visibility for your research: over $100 \mathrm{M}$ website views per year

At $\mathrm{BMC}$, research is always in progress.

Learn more biomedcentral.com/submissions 